\title{
Effect of exogenous gibberellin on reserve accumulation during the seed filling stage of oilseed rape
}

X.Q. Huang', R.Q. He', X.Y. Liao' ${ }^{1}$, B. Zhou' ${ }^{1}$, W.S. Peng ${ }^{3}$, J.Z. Lin ${ }^{1}$, D.Y. Tang ${ }^{1}$, Y.H. Zhu' ${ }^{1}$ X.Y. Zhao ${ }^{1}$ and X.M. Liu ${ }^{1,2}$

${ }^{1}$ Hunan Province Key Laboratory of Plant Functional Genomics and Developmental Regulation, College of Biology, Hunan University, Changsha, Hunan, China

${ }^{2}$ State Key Laboratory of Chemo/Biosensing and Chemometrics, Hunan University, Changsha, Hunan, China

${ }^{3}$ Academy of Seed Industry of Hunan Yahua, Changsha, Hunan, China

Corresponding authors: X.Y. Zhao / X.M. Liu

E-mail: zxy_mm@163.com/xmL05@hnu.edu.cn

Genet. Mol. Res. 13 (2): 2827-2839 (2014)

Received September 10, 2013

Accepted November 10, 2013

Published January 22, 2014

DOI http://dx.doi.org/10.4238/2014.January.22.7

\begin{abstract}
Exogenous gibberellins (GAs) are widely applied to increase crop yields, with knowledge about the physiological functioning and biochemistry mechanisms of these phytohormones improving; however, information remains limited about the effect of GAs on seed filling. In this study, the siliques (containing the seeds) of oilseed rape (Brassica napus L.) were treated with $\mathrm{GA}_{3}$ at 3 stages of seed filling. We confirmed that $\mathrm{GA}_{3}$ regulates the deposition of storage reserves in developing seeds. The percentage of crude fat in the seeds increased during the early stage, but remained stable during the middle and late stages. In comparison, the percentage of total protein decreased during the early and middle stages, but significantly increased during the late stage. In addition, Q-PCR was employed to analyze the expression level of related genes in
\end{abstract}


response to $\mathrm{GA}_{3}$. It was found that the expression of $W R I$ and $A B I 3$ transcription factors corresponded to crude fat content and total protein content, respectively. The expression of storage reserve related genes DGAT, MCAT, SUC2, and GPT was consistent with crude fat content, whereas the expression of Napin corresponded to total protein content. The results of this study indicate that exogenous $\mathrm{GA}_{3}$ has a different effect on storage reserve deposition in seed during different stages of seed filling, and the effect might be achieved via changing the expression of related genes.

Key words: Gibberellin; Reserve accumulation; Gene expression; Seed filling; Oilseed rape

\section{INTRODUCTION}

Gibberellins (GAs) are important phytohormones that are involved in regulating many aspects of plant development, such as seed germination, stalk elongation, leaf extension, flowering time, and fruit maturation (Kahn et al., 1957; Davies, 1995). Today, GAs are widely applied in agricultural processes to increase crop yield. GAs are frequently used to increase fruit and vegetable weight and yields, such as tomato (Naeem et al., 2001), in addition to increasing the 1000 grain weights of Bashaier, a drought tolerant maize genotype (Shaddad et al., 2011). The GA content varies in different plant organs, and is primarily abundant in the meristem, particularly the seed at maturity (Csukasi et al., 2011). There is evidence that the gibberellin/ abscisic acid balance regulates the germination versus maturation pathways during the seed development of maize (White et al., 2000). Active GA in the endosperm is essential for the normal seed development of Arabidopsis (Singh et al., 2010); yet, its regulating mechanism remains poorly understood.

Oilseed rape (Brassica napus L.) is an important oil crop worldwide, and forms an important component of our diets, as well as in the bio-energy sector. Previous studies have indicated that GAs regulate oilseed rape shoot elongation, in addition to controlling shoot elongation responses to light conditions (Potter et al., 1999). GAs end seed dormancy by accelerating the early germination of rapeseed (Fu and Lu, 1991); yet, little is known about the effect of GAs on the seed development of rapeseed.

In the seed storage reserves of oilseed rape, lipids are the predominant component, followed by storage proteins and saccharides. The accumulation of reserves is a complicated process, involving carbon partitioning among oil, storage proteins, and carbohydrates. During seed filling, sucrose is transported from the leaves to the seeds, and then it is broken into monosaccharides for use as a source for the synthesis of different storage products. To date, there is a paucity of studies about the regulation of seed storage reserve deposition by GAs.

Here, we investigated the effect of GAs on seed development and storage production accumulation. Specifically, we treated the siliques (containing the seeds) of oilseed rape with $\mathrm{GA}_{3}$ at 3 different stages of seed filling. At each stage, we measured the contents of the seed storage reserves, including crude fat, total protein, total sugar, and glucosinolates. The expression levels of genes related to storage reserve accumulation were analyzed. 


\section{MATERIAL AND METHODS}

\section{Plant material}

The seeds of a conventional oilseed rape cultivar W6 (Brassica napus L.) were obtained from the Academy of Seed Industry of Hunan Yahua, China. W6 has a 200 day growth cycle in Southern China, with a 40 day period from flowering to seed harvest. The seeds were sown $0.5 \mathrm{~m}$ apart in the experimental field of Hunan University in Changsha on 11/10/2009. Changsha $\left(28^{\circ} 12^{\prime} \mathrm{N}\right.$ latitude, $112^{\circ} 59^{\prime} \mathrm{E}$ longitude) belongs to the subtropical zone, and has a humid monsoon climate. The experimental plot contained 4 treatments, with 3 replicates, and a random block design, with a total of 12 zones. Each zone covered an area of 4 x $5 \mathrm{~m}$, with $0.5 \mathrm{~m}$ cell intervals, with 30 seedlings remaining after thinning. During flowering in April 2010, all of the flowers that blossomed on the same day from the main inflorescence were self-pollinated and marked.

\section{$\mathrm{GA}_{3}$ treatment}

The siliques of oilseed rape at 15 DAF (days after flowering), $25 \mathrm{DAF}$, and $35 \mathrm{DAF}$ (Figure 1), representing the early, middle, and later stages of seed filling, respectively, were selected for $\mathrm{GA}_{3}$ treatment. One hundred micromolar $\mathrm{GA}_{3}$ solution was used in this experiment, following the methods used in previous studies by our research group (Zhao et al., 2010; Zhou et al., 2011). The siliques were either treated with $\mathrm{GA}_{3}$ solution or distilled water (control) using a small brush from 9:00 a.m. to 9:30 a.m. About 10 of the treated siliques were sampled 3 $\mathrm{h}$ later, immediately frozen in liquid nitrogen, and stored at $-80^{\circ} \mathrm{C}$ for RNA extraction.
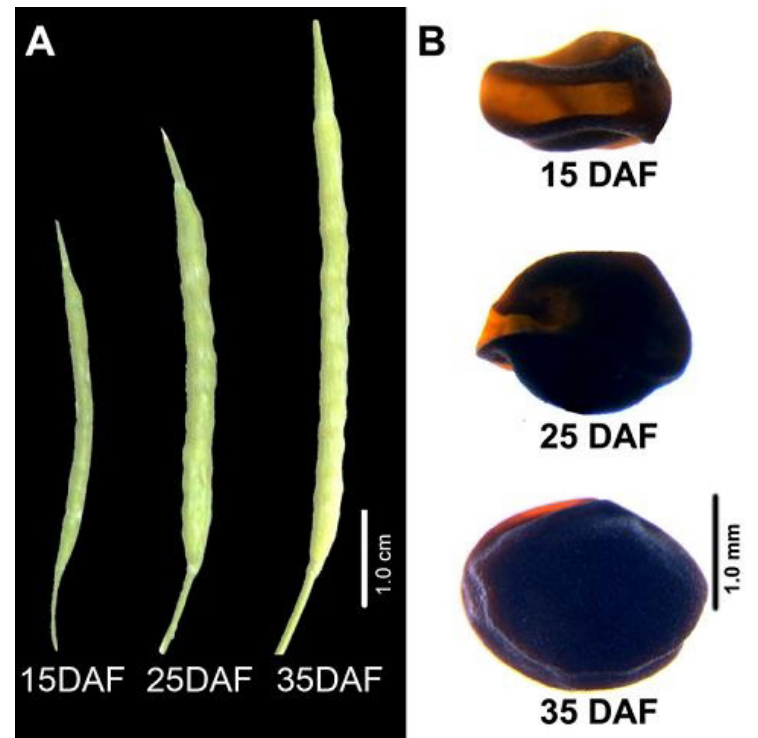

Figure 1. Fresh siliques and dry seeds used in this article. Fresh siliques and dry seeds: A. Three fresh siliques respectively represent the early, middle, and later stage of maturing siliques (15, 25 and 35 DAF). B. Dry seeds taken separately from three stages of maturing siliques. 


\section{Evaluation of seed related traits and measurement of storage reserves}

The treated siliques were harvested at $40 \mathrm{DAF}$, oven-dried at $60^{\circ} \mathrm{C}$ until a constant weight was reached. Subsequently, the length and weight of the siliques, in addition to the 1000 seed weight, were measured. Ten individual plants from each zone were randomly selected for the evaluation of these seed related traits. All of the seeds from the 4 treatments were used in the measurement of storage reserves.

The crude fat content of seeds was determined using a Soxhlet extractor, as described by von Soxhlet (1879). Total protein was detected using the Micro-Kjeldahl method, as described by Stuart (1936), using fully automatic Kjeldahl apparatus (Shanghai HongJi Instrument Co Ltd, Shanghai, China). Total sugar was measured by Anthrone-sulfuric acid colorimetry (Grande et al., 1953). Glucosinolate content was determined by Fourier transform near-infrared reflectance (NIR) spectroscopy (Font et al., 2004). Three parallel experiments were carried out for the measurement of storage reserves.

\section{Transcript level analysis}

Total RNA was extracted from the siliques using an Easy Way RNA Plant Mini Kit (Ambiogen Co. Ltd., San Jose, USA), and were treated with RNase-free DNase I (Promega Biotech Co., Fitchburg, USA). First-strand cDNA was reverse transcribed from the Dnase-digested RNA samples using an M-MLV Reverse Transcript Kit and an Oligo(dT) 18 primer, following manufacturer protocols (Life Technologies Co., Carlsbad, USA). QPCR reactions were performed by the SYBR Green PCR Master Mix (ABI, Inc., London, England) in an Mx3000P QPCR System (Agilent Technologies, Inc., Santa Clara, USA). The housekeeping gene Actin 7 was amplified as an internal control. PCR were completed at $94^{\circ} \mathrm{C}$ denaturation for $10 \mathrm{~min}$, followed by 40 cycles at $94^{\circ} \mathrm{C}$ denaturation for $30 \mathrm{~s}$, $58^{\circ} \mathrm{C}$ annealing for $20 \mathrm{~s}$, and $72^{\circ} \mathrm{C}$ elongation for $20 \mathrm{~s}$. Triplicate sets of PCR samples were carried out. The DNA sequences of all of the primers used in this study were listed in Table S1.

To determine whether the changes of seed reserve compositions in response to $\mathrm{GA}_{3}$ could be a result of altered genes expression, the expression profiles of 27 genes was analyzed. Among them, 5 genes are master seed transcription factors (LEC1, LEC2, FUS3, ABI3, and $W R I$ ), which control seed development and filling; 13 genes are oil biosynthesis genes including 3 ACCase genes (homomeric acetyl-CoA carboxylase $[A C C]$, alpha-carboxyltransferase $[\alpha-C T]$ and beta-carboxyltransferase $[\beta-C T]), 6$ genes involved in fatty acid elongation (Malonyl CoA-acyl carrier protein transacylase [MCAT], beta-ketoacyl-ACP synthase I [KASI], beta-ketoacyl-ACP synthase II [KASI], beta-ketoacyl-ACP synthase III [KASW], fatty acid elongase 1 [FAE1], and 3-ketoacyl-CoA reductase [KCR2]), 3 desaturases (stearoyl-ACP desaturase $[S A D]$, oleate desaturase [FAD2], and linoleate desaturase [FAD3]) and diacylglycerol acyltransferase [DGAT]; 6 genes is involved in carbohydrate metabolism including ADPglucose pyrophosphorylase $(A G P)$, sucrose transporter 2 (SUC2), Glc-6-P translocator $(G P T)$, fructose-bisphosphate aldolase 1 (Aldolase1), chloroplast pyruvate kinase beta subunit $(P K$ $\beta$ ), and pyruvate dehydrogenase E1 alpha subunit (PDE1a); 2 genes are major storage protein genes (Cruciferin and Napin); and a gene is a Cytochrome P450 gene named CYP79B5 (P450) which is related to glucosinolate biosynthesis. 


\section{Statistical analysis}

Sources of variance were conducted for silique length, silique weight, 1000 seed weight, and seed storage reserves content. Data were analyzed using Microsoft Excel 2003. Treatments were considered as fixed effects. The relative expression level of each gene in each treatment was calculated using the Mxpro software from the QPCR System (Agilent Technologies, Inc., Santa Clara, USA). Significant differences were determined using student's $t$-test. The software Originpro 8 (OriginLab Corporation, Northampton, USA) and Photoshop (Adobe Systems, Inc., San Jose, USA) were employed to construct graphs.

\section{RESULTS}

\section{Effects of $\mathrm{GA}_{3}$ on seed related traits and reserve accumulation in oilseed rape}

As shown in Table 1, the dry weight of the siliques was higher in all $\mathrm{GA}_{3}$-treated samples compared to the control. The dry weight increased by 12.16 and $16.04 \%$ for treated $\mathrm{GA}_{3}$ at $25 \mathrm{DAF}$ and $35 \mathrm{DAF}$, respectively. In addition, the length of the siliques increased by $3.46,4.45$, and $8.76 \%$ in the 3 respective $\mathrm{GA}_{3}$-treated samples. However, the 1000 seed weight decreased by almost $7 \%$ in the $25 \mathrm{DAF}$ and $35 \mathrm{DAF} \mathrm{GA}_{3}$-treated samples, while no difference was found for the $15 \mathrm{DAF}$.

\begin{tabular}{|c|c|c|c|c|}
\hline Treatment ${ }^{\S}$ & $-\mathrm{GA}^{\S}$ & 15DAF+GA & $25 \mathrm{DAF}+\mathrm{GA}$ & $35 \mathrm{DAF}+\mathrm{GA}$ \\
\hline Dry silique weight $(\mathrm{mg})^{\ddagger}$ & $91.33 \pm 3.141$ & $92.61 \pm 2.820$ & $102.44 \pm 2.143^{* *}$ & $105.98 \pm 2.494^{* *}$ \\
\hline Silique length $(\mathrm{cm})^{\neq}$ & $4.72 \pm 0.058$ & $4.88 \pm 0.086$ & $4.93 \pm 0.049^{* *}$ & $5.13 \pm 0.073^{* *}$ \\
\hline Thousand seed weight $(\mathrm{g})^{\dagger \dagger}$ & $2.19 \pm 0.004$ & $2.16 \pm 0.005$ & $2.04 \pm 0.009^{* *}$ & $2.04 \pm 0.008^{* *}$ \\
\hline Crude fat content $(\%)^{i \dagger}$ & $36.58 \pm 0.254$ & $38.30 \pm 0.360^{* *}$ & $37.01 \pm 0.170$ & $36.35 \pm 0.073$ \\
\hline Total protein content $(\%)^{\dagger \dagger}$ & $23.58 \pm 0.277$ & $22.83 \pm 0.146$ & $22.22 \pm 0.269^{* *}$ & $24.96 \pm 0.185^{*}$ \\
\hline Total sugar content $(\%)^{\dagger \dagger}$ & $10.74 \pm 0.097$ & $11.62 \pm 0.174^{* *}$ & $11.28 \pm 0.120^{*}$ & $11.29 \pm 0.110^{*}$ \\
\hline Glucosinolates content $(\mu \mathrm{mol} / \mathrm{g})^{\dagger \dagger}$ & $42.88 \pm 0.944$ & $58.50 \pm 0.491^{* *}$ & $56.65 \pm 0.385^{* *}$ & $63.43 \pm 0.185^{* *}$ \\
\hline
\end{tabular}

*Significant at the 0.05 probability level. ${ }^{*}$ Significant at the 0.01 probability level. ${ }^{\S}$-GA $=$ siliques treated with distilled water (control); $+\mathrm{GA}=$ siliques treated with $\mathrm{GA}_{3}$; $\mathrm{DAF}=$ days after flowering. * Each data point is reported as means $\pm \mathrm{SD}$ of 30 siliques. ${ }^{\dagger}$ Each data point is reported as means $\pm \mathrm{SD}$ of three replicates.

The storage reserves of the seeds (including crude fat, total protein, total sugar, and glucosinolates) also changed in response to $\mathrm{GA}_{3}$. The crude fat content of the seeds increased by $4.70 \%$ in the 15 DAF samples, whereas little change was observed in the 25 DAF and 35 DAF samples. Total protein content decreased by 3.18 and $5.77 \%$ in the 15 DAF and 25 DAF samples, but increased by $5.85 \%$ in the $35 \mathrm{DAF} \mathrm{GA}_{3}$-treated sample. Total sugar content increased by $6.77,4.10$, and $5.04 \%$ the 3 respective treatments. Glucosinolate content was remarkably enhanced by $\mathrm{GA}_{3}$-treatment, showing a $36.43,32.11$, and $47.92 \%$ increase at 15 , 25 , and $35 \mathrm{DAF}$, respectively.

\section{Expression of master seed transcript factors in response to $\mathrm{GA}_{3}$}

The transcriptional levels of 4 genes ( $L E C 1, L E C 2, F U S 3$, and $W R I)$ were upregulated 
in the 15 DAF samples, with $L E C 2$ and WRI noticeably increasing 101.9 and $104.4 \%$ compared to the control (Figure 2). Yet, the expression of $A B I 3$ was suppressed in the $15 \mathrm{DAF}$ sample. The transcripts of 4 of these genes (excluding $W R I$ ) were suppressed by GA treatment at $25 \mathrm{DAF}$, showing a decrease of 51.6-84.1\%. In contrast, GA treatment at 35 DAF resulted in the upregulation of the mRNA levels of FUS3 and $A B I 3$, while $L E C 1, L E C 2$, and $W R I$ were downregulated.

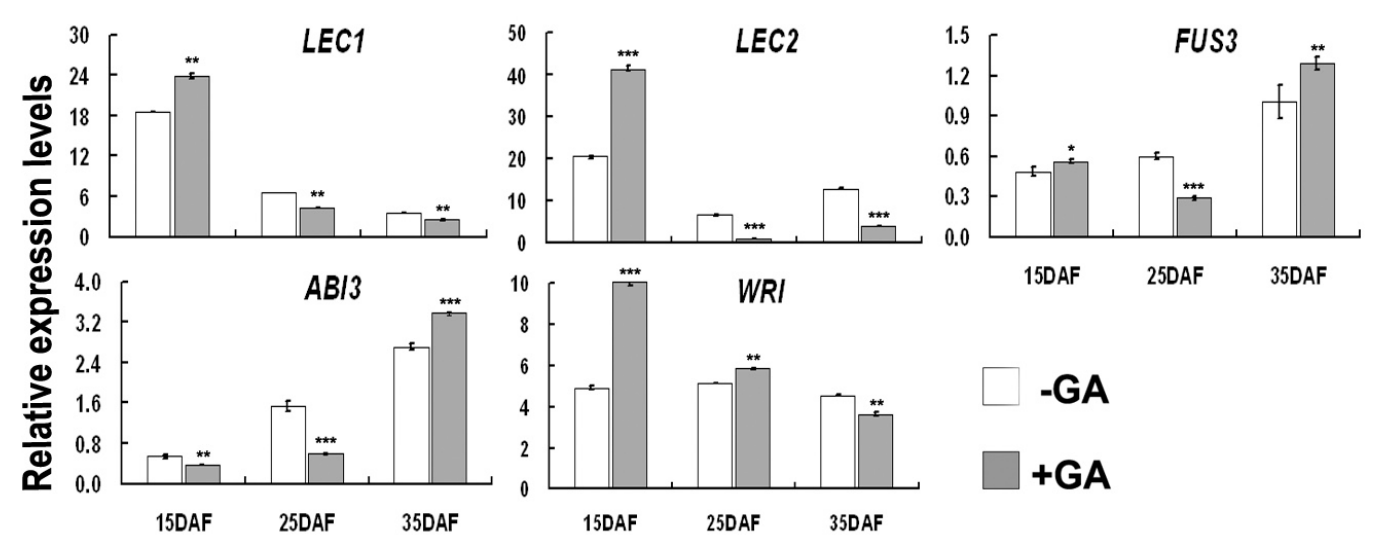

Figure 2. Effects of GA3 on transcript levels of genes encoding master seed transcript factors during siliques maturing. Total RNA was extracted from the 15, 25 and 35 DAF (Days after flowering) siliques treated by $\mathrm{GA}_{3}$ solution or distilled water (control) for $3 \mathrm{~h}$, and used for Q-PCR analysis. The housekeep gene Actin 7 was amplified as an internal control. Three replicates were carried out on cDNA template dilutions which obtained from three independent total RNA extractions. The error bars represent the standard deviations. $* \mathrm{P}<0.05, * * \mathrm{P}<0.01,{ }^{*} * * \mathrm{P}$ $<0.001$, significant differences between the control and GA treatments. $-\mathrm{GA}=$ siliques treated with distilled water (control); $+\mathrm{GA}=$ siliques treated with $\mathrm{GA}_{3}$.

\section{Expression of oil synthesis genes in response to $\mathrm{GA}_{3}$}

It was found that the transcription levels of all these indicated genes altered in response to $\mathrm{GA}_{3}$ at the 3 different stages during seed filing (Figure 3 ).

In response to $\mathrm{GA}_{3}$ at $15 \mathrm{DAF}$, the transcription levels of 3 genes $(\beta-C T, M C A T$, and $D G A T$ ) were upregulated, with noticeable increases of $42.0,55.3$, and $108.9 \%$, respectively. Seven genes ( $\alpha-C T, K A S I, K A S I, K A S W$, KCR2, FAD2, and FAD3) were downregulated, with noticeable decreases of $30.0,50.1,55.9$, and $76.3 \%$ for the $\alpha-C T, K A S I, K A S \Pi$, and FAD, respectively.

In response to $\mathrm{GA}_{3}$ at $25 \mathrm{DAF}$, the transcription levels of 4 genes (ACC, $\beta$-CT, MCAT, and FAD2) were upregulated, while those of four genes (KASח, SAD, FAD3, and KCR2) were downregulated by more than $20 \%$. Among these, $A C C$ and $\beta$ - $C T$ increased by 64.1 and $89.9 \%$, respectively, while $K A S \Pi, S A D$, and $F A D 3$ decreased by $41.8,46.2$, and $47.5 \%$, respectively.

In response to $\mathrm{GA}_{3}$ at $35 \mathrm{DAF}$, the transcription levels of 4 genes (ACC, $\alpha-C T, \beta-C T$, and $S A D$ ) were upregulated, while those of 6 genes (KAS I, KAS UI, MACT, FAE 1, KCR2, and FAD3) were downregulated by more than $20 \%$. The expression levels of $A C C, \alpha-C T$, and $\beta$-CT noticeably increased by $119.7,138.4$, and $201.9 \%$, respectively. Interestingly, genes involved in fatty acid elongation (KASI, KAS $W, M A C T$, FAE1, and KCR2) showed a noticeable decline of $45.6,40.1,51.6,75.1$, and $38.8 \%$, respectively. 


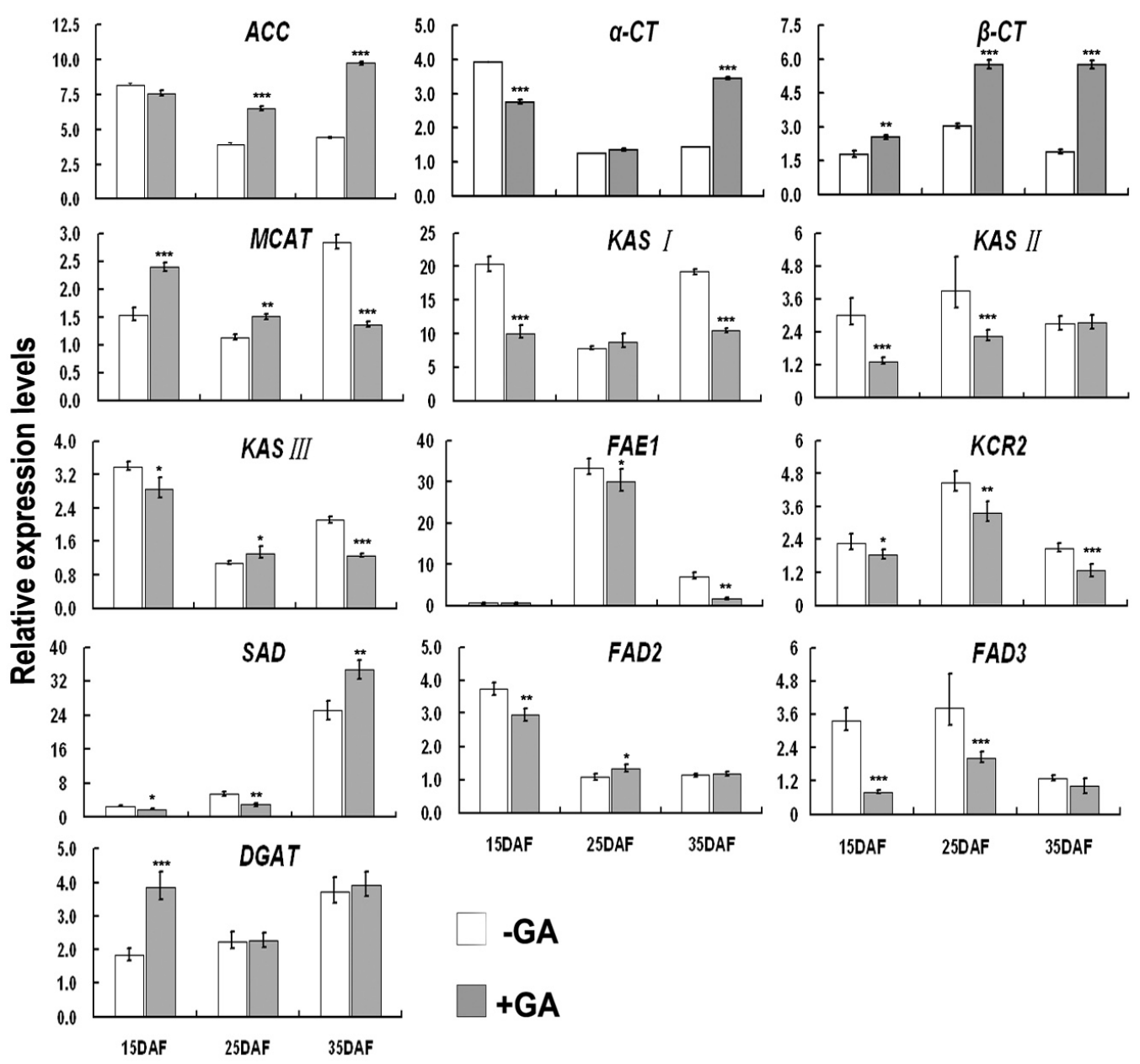

Figure 3. Effects of $\mathrm{GA}_{3}$ on transcript levels of oil synthesis genes during siliques maturing. Total RNA was extracted from the 15, 25 and $35 \mathrm{DAF}$ (days after flowering) siliques treated by GA solution or distilled water (control) for 3h, and used for Q-PCR analysis. The housekeep gene Actin 7 was amplified as an internal control. Three replicates were carried out on cDNA template dilutions which obtained from three independent total RNA extractions. The error bars represent the standard deviations. $* \mathrm{P}<0.05, * * \mathrm{P}<0.01, * * * \mathrm{P}<0.001$, significant differences between the control and GA treatments. $-\mathrm{GA}=$ siliques treated with distilled water (control); $+\mathrm{GA}=$ siliques treated with $\mathrm{GA}_{3}$.

\section{Expression of carbohydrates metabolism-related genes, storage protein genes, and gene $P 450$ in response to $\mathrm{GA}_{3}$}

As shown in Figure 4, in the 15 DAF samples, GPT and SUC2 were upregulated by 53.4 and $37.2 \%$, Aldolase 1 and $P K-\beta$ were downregulated by 28.3 and $36.9 \%$, and $A G P$ and $P D E 1 a$ remained relatively stable. In the $25 \mathrm{DAF}$ samples, the expressions of $A G P$ and $A l$ dolasel became upregulated by 112.1 and $61.7 \%, P K-\beta$ remained downregulated by $37.8 \%$, 
and the other 3 genes (GPT, SUC2, and PDE1a) remained relatively unchanged. In the 35 DAF samples, the expression of $P K-\beta$ was upregulated by $34.9 \%$, but $S U C 2$, Aldolase 1, and $P D E 1 a$ were downregulated by $42.5,39.4$, and $37.1 \%$, respectively. GPT was slightly downregulated, and $A G P$ remained relatively stable.

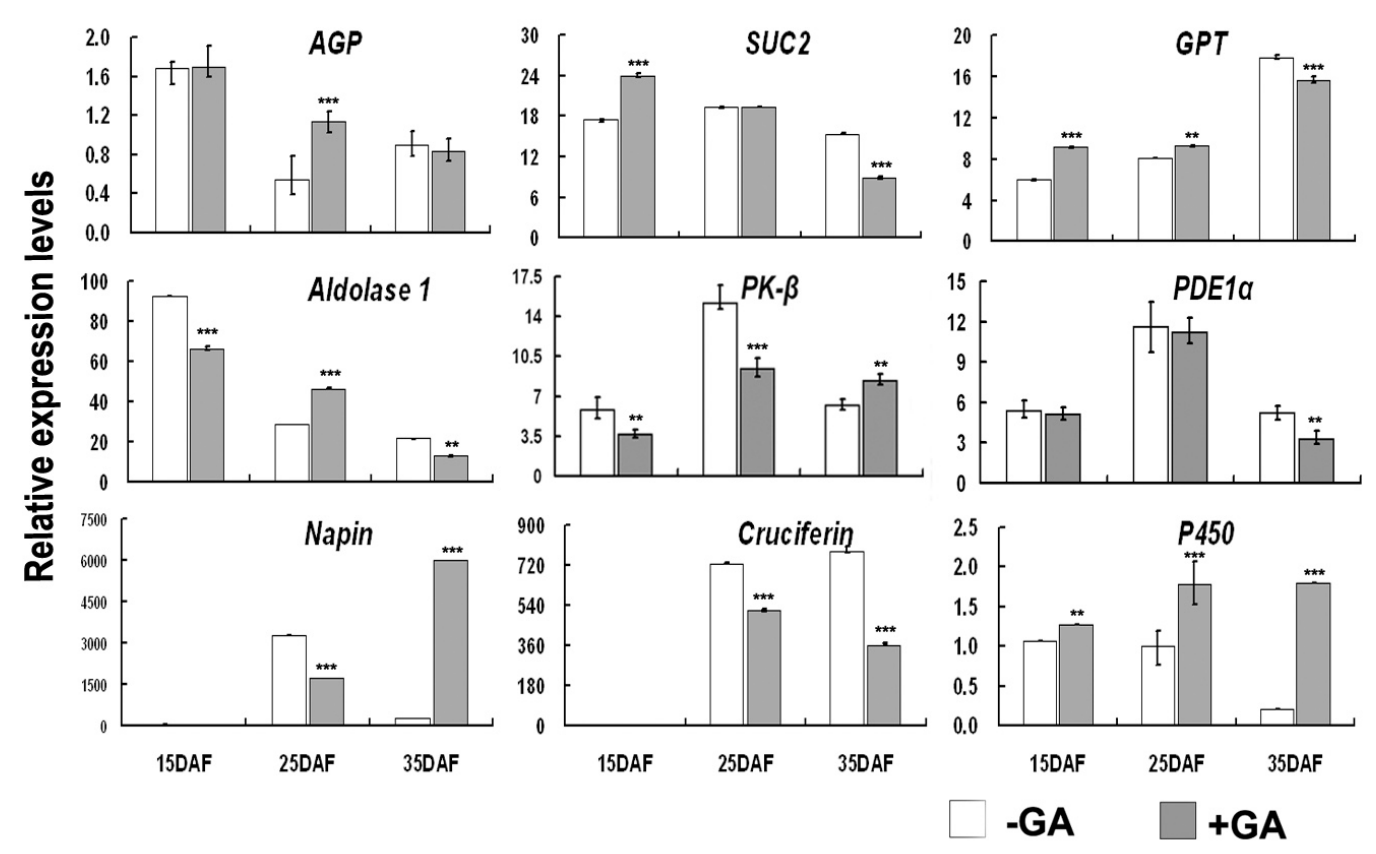

Figure 4. Effects of $\mathrm{GA}_{3}$ on transcript levels of several genes respectively related with carbohydrates metabolism, storage protein and glucosinolates deposition during siliques maturing. Total RNA was extracted from the 15, 25 and $35 \mathrm{DAF}$ (days after flowering) siliques treated by $\mathrm{GA}_{3}$ solution or distilled water (control) for $3 \mathrm{~h}$, and used for Q-PCR analysis. The housekeep gene Actin 7 was amplified as an internal control. Three replicates were carried out on cDNA template dilutions which obtained from three independent total RNA extractions. The error bars represent the standard deviations. ${ }^{*} \mathrm{P}<0.05,{ }^{*} \mathrm{P}<0.01,{ }^{*} * \mathrm{P}<0.001$, significant differences between GA treatments and the control. $-\mathrm{GA}=$ siliques treated with distilled water (control); $+\mathrm{GA}=$ siliques treated with $\mathrm{GA}_{3}$.

The transcription levels of Cruciferin and Napin, which encode 2 major storage proteins (Cruciferin and Napin) in oilseed rape, were also detected in this study. Both genes showed almost no expression in the $15 \mathrm{DAF}$ and control samples, and were downregulated by 47.6 and $28.8 \%$ in the 25 DAF samples. In the 35 DAF samples, the transcription of Cruciferin remained downregulated (by 53.8\%), whereas that of Napin expressed a noticeable 20-fold increase (Figure 4).

It was found that the expression of $P 450$ was upregulated by $20.0,77.8$, and $759.1 \%$ in response to $\mathrm{GA}_{3}$ at 15,25 , and $35 \mathrm{DAF}$, respectively (Figure 4). This result is consistent with the increased glucosinolate content recorded in the seeds of $\mathrm{GA}_{3}$ treated samples (Table 1).

\section{DISCUSSION}

GAs are used to improve the productivity of various crops. For instance, it is used to gener- 
ate larger fruits in orange and grape crops. In this study, longer and heavier siliques were observed in oilseed rape treated with $\mathrm{GA}_{3}$ (Table 1). Seed weight is an important agricultural trait that is related to seed yield per plant in oilseed rape (Yang et al., 2012). Previous reports found that seed weight is not affected by GA-deficiency (Barendse et al., 1986). In the current study, we found the 1000 seed weight was not affected by $\mathrm{GA}_{3}$ treatment at $15 \mathrm{DAF}$, but that it was reduced by $\mathrm{GA}_{3}$ at 25 and 35 DAF. The analysis of heavier siliques (containing seeds) (Table 1) indicated that exogenous $\mathrm{GA}_{3}$ might accelerate nutrient flow to the silique, but not the actual seed at 25 and 35 DAF.

Carbohydrates, proteins, and lipids are considered to be the 3 predominant component storage units of seed reserves. A previous study on the fern Ceratopteris thalictroides L. demonstrated that GA stimulates the accumulation of starch in mature leaves (Stein, 1971). In this study, we showed that $\mathrm{GA}_{3}$ treatment modified the percentages of proteins and lipids in the seeds. In addition, $\mathrm{GA}_{3}$ stimulated the total sugar and glucosinolates accumulation in the seeds. Previous studies by our research group indicated that the heterologous expression of AtGA20x8, which is a GA inactivation gene, in oilseed rape enhanced photosynthetic capacity (Zhou et al., 2011), siliques, seed yield, and seed oil content, but decreased glucosinolate content (Zhao et al., 2010; Zhou et al., 2012). These findings in combination with the results of the current study indicate that both endogenous and exogenous GAs regulate seed development, seed storage accumulation, and glucosinolate synthesis.

\section{Master seed transcription factors}

Previous studies have shown that many elementary seed development processes are regulated by the $L E C 1 /(A B I 3 / F U S 3 / L E C 2)-B 3$ network (Junker et al., 2010). It has been reported that the overexpression of $L E C 1$ in Arabidopsis generates increased levels of major fatty acid species and lipids (Mu et al., 2008). For instance, ectopic $L E C 2$ expression induces the accumulation of seed storage proteins and oil bodies in vegetative and reproductive organs (Stone et al., 2008). The Arabidopsis lec 2 mutant was found to have 30\% less oil and 15\% less protein (Angeles-Nunez and Tiessen, 2011). The results of the current study showed that $L E C 1$ and $L E C 2$ were significantly upregulated by $\mathrm{GA}_{3}$ at $15 \mathrm{DAF}$, but downregulated at $25 \mathrm{DAF}$ and $35 \mathrm{DAF}$. Based on the deposition of crude fats and total proteins (Table 1), LEC1 and LEC2 might regulate lipid synthesis at the early stage and late seed filling stages, and regulate storage proteins during the middle stage.

$W R I$ is a transcriptional activator that is involved in oil accumulation during seed development, by regulating the activation of a subset of sugar-responsive genes and oil synthesis genes (Focks, 1998; Baud et al., 2009). In response to $\mathrm{GA}_{3}$, this activator was upregulated by 104.4 and $13.4 \%$ in the 15 DAF and 25 DAF treatments, but was downregulated by $20.8 \%$ in the 35 DAF treatment, which corresponds with the observed changes in seed oil content (Table 1). WRI might play an important role in seed oil synthesis in response to $\mathrm{GA}_{3}$.

$A B I 3$ and FUS3 regulate the expression of storage protein genes, such as At2S and Cruciferin, in an ABA (Abscisic Acid) dependent manner (Kagaya et al., 2005b). The two genes are required for $L E C l$ to regulate seed storage protein genes (Kagaya et al., 2005a). Here, we showed that the total protein content is highly consistent with the expression pattern of $A B I 3$ in response to $\mathrm{GA}_{3}$.

\section{Oil biosynthesis related genes}

ACCase is essential for the malonyl-CoA supply of fatty acid biosynthesis (Brownsey 
et al., 1997), with high ACCase mRNAs tissue accumulations indicating highly active of fatty acids biosynthesis (Ke et al., 2000a). The Q-PCR results of the current study showed that the changes in expression of ACCase genes $(A C C, \alpha-C T$, and $\beta-C T)$ were negatively correlated with changes in oil content in response to $\mathrm{GA}_{3}$. In comparison, previous studies found that lipid accumulation is not substantially affected by the altered expression of ACCase genes (Roesler et al., 1997; Thelen and Ohlrogge, 2002). Thus, no significant correlation exists between ACCase genes and lipid accumulation.

MCAT, ACP, and KASIII are 3 enzymes considered essential for the initiation of fattyacid biosynthesis by fatty acid synthase II (FASII) (Prigge et al., 2003). Here, we found that the transcription pattern of MCAT was consistent with the observed changes in oil content in response to $\mathrm{GA}_{3}$. KASI and KASח catalyze the fatty acid elongation step from 4:0-ACP to 18:0-ACP in the plastid (Yasuno et al., 2004). Subsequently, FAE extends the chain length of fatty acids from $\mathrm{C} 18$ to $\mathrm{C} 20$ and $\mathrm{C} 22$. The results of the Q-PCR analysis of this study showed that the expressions of 3 fatty acid elongase genes (KASI, KASI, KASW) and 2 genes from the FAE multienzyme complex (FAE1 and $K C R 2$ ) were mostly downregulated at all 3 stages in $\mathrm{GA}_{3}$-treated samples, except for $K A S I$ and $K A S W$ in the $25 \mathrm{DAF} \mathrm{GA}_{3}$ treatment, which were upregulated. This observation indicates that $\mathrm{GA}_{3}$ partly regulates fatty acid synthesis by suppressing the expression of fatty acid elongase genes.

$D G A T$ plays a key role in lipid accumulation. Seed oil content decreases when DGAT is silent (Zhang et al., 2005), and increases when DGAT is overexpressed (Taylor et al., 2009). The Q-PCR results of the current study showed that the expression pattern of DGAT (Figure 3) was consistent with the observed changes in the oil content (Table 1) of the $\mathrm{GA}_{3}$-treated samples.

The 3 fatty acid desaturases, SAD, FAD2, and FAD3, are believed to control the production of oleic acid (18:1), linoleic acid (18:2), and linolenic acid (18:3), respectively, in plants (McKeon and Stumpf, 1982; Browse et al., 1993; Okuley et al., 1994; Nabloussi et al., 2005). The results of the current study showed that all 3 genes were suppressed by $\mathrm{GA}_{3}$ in the $15 \mathrm{DAF}$ and $25 \mathrm{DAF}$ treatments, but that only $S A D$ was noticeably upregulated in the $35 \mathrm{DAF}$ treatment. Overall, $\mathrm{GA}_{3}$ might contribute towards downregulating the unsaturation of fatty acids during the early stage of seed filling.

\section{Carbohydrate metabolism}

AGP catalyzes the formation of ADP-Glc, and ADP-Glc is the substrate of starch synthases; hence, the inactivation of $A G P$ would lead to a decline in starch levels and an increase in TAG levels (Li et al., 2010). In our study, the expression of $A G P$ remained stable in the 15 DAF and 35 DAF treatments, but was noticeably upregulated by $\mathrm{GA}_{3}$ in the 25 DAF treatment. This result indicates the absence of a clear relationship between $A G P$ expression and total sugar accumulation in $\mathrm{GA}_{3}$ treated seeds (Table 1).

SUC2 is a major sucrose transporter that is essential for phloem loading (Srivastava et al., 2008). The silencing of $S U C 2$ might block carbohydrate export from the leaves (Riesmeier et al., 1994). During carbon partitioning, $G P T$ contributes to importing glucose 6-phosphate into the plastids of non-green tissues (Niewiadomski et al., 2005). In this study, SUC2 and $G P T$ were upregulated by $\mathrm{GA}_{3}$ in the 15 DAF treatment, remained almost unchanged in the 25 DAF treatment, and were downregulated in the $35 \mathrm{DAF}$ treatment. These results indicate the strong correlation of these transporters with crude fats deposition (Table 1). 
Glycolysis is central to carbon partitioning, because it converts sugars into precursors for the synthesis of storage reserves. Aldolase 1 is a glycolytic enzyme that is involved in the hexose cleavage reaction, with its activity increasing in rice roots treated with $\mathrm{GA}_{3}$ (Komatsu et al., 2004). Plastidic pyruvate kinase catalyzes the conversion of phosphoenolpyruvate to pyruvate during ATP production, and is involved in the biosynthesis of seed oil (Andre et al., 2007). PDE1a is the alpha subunit of Pyruvate dehydrogenase E1, which plays an important role in acetyl-CoA formation during the synthesis of lipids in seeds (Ke et al., 2000b). The results of our Q-PCR analysis showed that Aldolase 1 was downregulated by $\mathrm{GA}_{3}$ in the 15 and $35 \mathrm{DAF}$ treatments, but that its transcription levels were enhanced in the $25 \mathrm{DAF}$ treatment. PK- $\beta$ was suppressed in the 15 and 25 DAF treatments, but was upregulated in the 35 DAF treatment. PDE1a was weakly influenced by $\mathrm{GA}_{3}$ in the 15 and $25 \mathrm{DAF}$ treatments, but was suppressed in the 35 DAF treatment. A significant correlation was not shown by these 3 genes with either total sugar or crude fat accumulation in the $\mathrm{GA}_{3}$ treatments.

\section{Storage protein and glucosinolate-related genes}

Napin and Cruciferin are the 2 main types of storage proteins in oilseed rape. In this study, Cruciferin was downregulated by $\mathrm{GA}_{3}$ in the 25 and 35 DAF treatments. In contrast, Napin was suppressed by $\mathrm{GA}_{3}$ in the 15 and 25 DAF treatment (not shown in the figure), but noticeably increased in the 35 DAF treatment. We assumed that $\mathrm{GA}_{3}$ decreases total protein levels by suppressing the expression of these 2 genes during the early and middle stages of seed filling, and that it mainly increases total protein levels by regulating Napin expression during the late seed filling stage.

Glucosinolates are associated with the bitter taste of Brassicaceae (van Doorn et al., 1998). A previous study revealed that cytochrome P450 is important in the glucosinolate biosynthetic pathway (Du et al., 1995). In our study, the transcription pattern of P450 corresponded to changes in the glucosinolate content of seeds treated with $\mathrm{GA}_{3}$ at the 3 different stages of seed filling (Table 1).

In conclusion, exogenous $\mathrm{GA}_{3}$ application increases silique weight and length, in addition to the total sugar and glucosinolate content of seeds during seed filling; however, exogenous $\mathrm{GA}_{3}$ application has variable effects on the weight, crude fat content, and total protein content of seeds at the 3 stages of seed filling. In this study, the expression pattern of transcription factor $W R I$ and the 4 genes $D G A T, M C A T, S U C 2$, and GPT were correlated with crude fat content in response to $\mathrm{GA}_{3}$ treatment. In addition, the transcription factor $A B I 3$ and gene Napin were correlated with total protein content. These results provide new insights about the interaction between phytohormones and the synthesis pathways of plant reserve substances.

\section{ACKNOWLEDGMENTS}

Research supported by the National Natural Science Foundation of China (\#30800080), National High Technology and Development Program of China (\#2007AA10Z127), the Teaching and Science Research Program for Excellent Young Teachers in Colleges and Universities from Education Department of Hunan Province (2012), and The Cooperative Innovation Center of Engineering and New Products for Developmental Biology of Hunan Province (\#20134486). 


\section{Supplementary material}

\section{REFERENCES}

Andre C, Froehlich JE, Moll MR and Benning C (2007). A heteromeric plastidic pyruvate kinase complex involved in seed oil biosynthesis in Arabidopsis. Plant Cell 19: 2006-2022.

Angeles-Nunez JG and Tiessen A (2011). Mutation of the transcription factor LEAFY COTYLEDON 2 alters the chemical composition of Arabidopsis seeds, decreasing oil and protein content, while maintaining high levels of starch and sucrose in mature seeds. J. Plant Physiol. 168: 1891-1900.

Baud S, Wuilleme S, To A, Rochat C, et al. (2009). Role of WRINKLED1 in the transcriptional regulation of glycolytic and fatty acid biosynthetic genes in Arabidopsis. Plant J. 60: 933-947.

Barendse GWM, Kepczynski J, Karssen CM and Koomneef M (1986). The role of endogenous gibberellins during fruit and development: Studies on gibberellin-defident genotypes of Arabidopsis thaliana. Physiol. Plantarum 67: 315319.

Browse J, McConn M, James D Jr and Miquel M. (1993). Mutants of Arabidopsis deficient in the synthesis of alphalinolenate. Biochemical and genetic characterization of the endoplasmic reticulum linoleoyl desaturase. J. Biol. Chem. 268: 16345-51.

Brownsey RW, Zhande R and Boone AN (1997). Isoforms of acetyl-CoA carboxylase: structures, regulatory properties and metabolic functions. Biochem. Soc. Trans. 25: 1232-1238.

Csukasi F, Osorio S, Gutierrez JR, Kitamura J, et al. (2011). Gibberellin biosynthesis and signalling during development of the strawberry receptacle. New Phytol. 191: 376-90.

Davies PJ (1995). Plant Hormones: Physiology, Biochemistry and Molecular Biology Kluwer Academic Publishers, Dordrecht, The Netherlands.

Du L, Lykkesfeldt J, Olsen CE and Halkier BA (1995). Involvement of cytochrome P450 in oxime production in glucosinolate biosynthesis as demonstrated by an in vitro microsomal enzyme system isolated from jasmonic acidinduced seedlings of Sinapis alba L. Proc. Natl. Acad. Sci. U. S. A. 92: 12505-12509.

Focks N (1998). Wrinkled1: A novel, low-seed-oil mutant of Arabidopsis with a deficiency in the seed-specific regulation of carbohydrate metabolism. Plant Physiol. 118: 91-101.

Font R, Del RM, Fernandez-Martinez JM and De Haro-Bailon A (2004). Use of near-infrared spectroscopy for screening the individual and total glucosinolate contents in Indian mustard seed (Brassica juncea L. Czern. \& Coss.). J Agric. Food Chem. 52: 3563-3569.

Fu SZ and Lu ZJ (1991). Studies on seed dormancy in Brassica L. III. Effect of different germination stimulators and hot shock on breaking seed dormancy. Oil Crops Sci. 1007-9084: 31-34.

Grande F, Utrera A and De Oya JC (1953). Anthrone reaction in estimation of carbohydrates. Bull. Inst. Med. Res. Univ. Madr. 6: 67-81.

Junker A, Hartmann A, Schreiber F and Baumlein H (2010). An engineer's view on regulation of seed development. Trends Plant Sci. 15: 303-307.

Kagaya Y, Toyoshima R, Okuda R, Usui H, et al. (2005a). LEAFY COTYLEDON1 controls seed storage protein genes through its regulation of FUSCA3 and ABSCISIC ACID INSENSITIVE3. Plant Cell Physiol. 46: 399-406.

Kagaya Y, Okuda R, Ban A, Toyoshima R, et al. (2005b). Indirect ABA-dependent regulation of seed storage protein genes by FUSCA3 transcription factor in Arabidopsis. Plant Cell Physiol. 46: 300-311.

Kahn A, Goss JA and Smith DE (1957). Effect of gibberellin on germination of lettuce seed. Science 125: 645-646.

Ke J, Wen TN, Nikolau BJ and Wurtele ES (2000a). Coordinate regulation of the nuclear and plastidic genes coding for the subunits of the heteromeric acetyl-coenzyme A carboxylase. Plant Physiol. 122: 1057-1071.

Ke J, Behal RH, Back SL, Nikolau BJ, et al. (2000b). The role of pyruvate dehydrogenase and acetyl-coenzyme A synthetase in fatty acid synthesis in developing Arabidopsis seeds. Plant Physiol. 123: 497-508.

McKeon TA and Stumpf PK (1982). Purification and characterization of the stearoyl-acyl carrier protein desaturase and the acyl-acyl carrier protein thioesterase from maturing seeds of safflower. J. Biol. Chem. 257: 12141-12147.

Mu JY, Tan HL, Zheng Q, Fu FY, et al. (2008). LEAFY COTYLEDON1 is a key regulator of fatty acid biosynthesis in Arabidopsis. Plant Physiol. 148: 1042-1054.

Li Y, Han D, Hu G, Dauvillee D, et al. (2010). Chlamydomonas starchless mutant defective in ADP-glucose pyrophosphorylase hyper-accumulates triacylglycerol. Metab. Eng. 12: 387-391.

Naeem N, Ishtiaq M, Khan P, Mohammad N, et al. (2001). Effect of Gibberellic acid on growth and yield of tomato. $J$. Biol. Sci. 1: 448-450. 
Nabloussi A, Fernandez-Martinez JM and Velasco L (2005). Spatial and temporal expression of mutations for high oleic acid and low linolenic acid concentration in Ethiopian mustard. Crop Sci. 45: 202-208.

Okuley J, Lightner J, Feldmann K, Yadav N, et al. (1994). Arabidopsis FAD2 gene encodes the enzyme that is essential for polyunsaturated lipid synthesis. Plant Cell 6: 147-58.

Prigge ST, He X, Gerena L, Waters NC, et al. (2003). The initiating steps of a type II fatty acid synthase in Plasmodium falciparum are catalyzed by pfACP, pfMCAT, and pfKASIII. Biochemistry 42: 1160-1169.

Potter TI, Rood SB and Zanewich KP (1999). Light intensity, gibberellin content and the resolution of shoot growth in Brassica. Planta 207: 505-511.

Riesmeier JW, Willmitzer L and Frommer WB (1994). Evidence for an essential role of the sucrose transporter in phloem loading and assimilate partitioning. EMBO J. 13: 1-7.

Roesler K, Shintani D, Savage L, Boddupalli S, et al. (1997). Targeting of the Arabidopsis homomeric acetyl-coenzyme A carboxylase to plastids of rapeseeds. Plant Physiol. 113: 75-81.

Shaddad MAK, El-Samad MHA and Mohammed HT (2011). Interactive effects of drought stress and phytohormones or polyamines on growth and yield of two M (Zea maize L.) genotypes. Am. J. Plant Sci. 2: 790-807.

Singh DP, Filardo FF, Storey R, Jermakow AM, et al. (2010). Overexpression of a gibberellin inactivation gene alters seed development, KNOX gene expression, and plant development in Arabidopsis. Physiol. Plant 138: 74-90.

Stein DB (1971). Gibberellin-induced fertility in the fern Ceratopteris thalictroides (L.) Brongn. Plant Physiol. 48: 416418.

Srivastava AC, Ganesan S, Ismail IO, Ayre BG (2008). Functional characterization of the Arabidopsis AtSUC2 Sucrose/ $\mathrm{H}+$ symporter by tissue-specific complementation reveals an essential role in phloem loading but not in long-distance transport. Plant Physiol. 148: 200-11.

Stone SL, Braybrook SA, Paula SL, Kwong LW, et al. (2008). Arabidopsis LEAFY COTYLEDON2 induces maturation traits and auxin activity: Implications for somatic embryogenesis. Proc. Natl. Acad. Sci. U. S. A. 105: 3151-3156

Stuart NW (1936). Adaptation of the micro-kjeldahl method for the determination of nitrogen in plant tissues. Plant Physiol. 11: 173-179.

Taylor DC, Zhang Y, Kumar A, Francis T, et al. (2009). Molecular modification of triacylglycerol accumulation by overexpression of DGAT1 to produce canola with increased seed oil content under field conditions. Bot.-Botanique 87: 533-543.

Thelen JJ and Ohlrogge JB. (2002). Both antisense and sense expression of biotin carboxyl carrier protein isoform 2 inactivates the plastid acetyl-coenzyme A carboxylase in Arabidopsis thaliana. Plant J. 32: 419-431.

van Doorn HE, van der Kruk GC, van Holst G-J, Raaijmakers-Ruijs NCME, et al. (1998). The glucosinolates sinigrin and progoitrin are important determinants for taste preference and bitterness of brussels sprouts. J. Sci. Food Agric. 78: 30-38.

von Soxhlet F (1897). Die gewichtsanalytische Bestimmung des Milchfettes. Polytechnisches J. 232: 461-465.

White CN, Proebsting WM, Hedden P and Rivin CJ (2000). Gibberellins and seed development in maize. I. Evidence that gibberellin/abscisic acid balance governs germination versus maturation pathways. Plant Physiol. 122: 1081-1088.

Yang P, Shu C, Chen L, Xu J, et al. (2012). Identification of a major QTL for silique length and seed weight in oilseed rape (Brassica napus L.). Theor. Appl. Genet. 125: 285-96.

Yasuno R, von Wettstein-Knowles P, Wada H (2004). Identification and molecular characterization of the beta-ketoacyl[acyl carrier protein] synthase component of the Arabidopsis mitochondrial fatty acid synthase. J. Biol. Chem. 279: 8242-51.

Zhang FY, Yang MF and Xu YN (2005). Silencing of DGAT1 in tobacco causes a reduction in seed oil content. Plant Sci. 169: 689-694.

Zhao XY, Zhu DF, Zhou B, Peng WS, et al. (2010) Over-expression of the AtGA2ox8 gene decreases the biomass accumulation and lignification in rapeseed (Brassica napus L.). J. Zhejiang Univ. Sci. B 11:471-81.

Zhou B, Peng D, Lin JZ, Huang XQ, et al. (2011). Heterologous expression of a Gibberellin 2-Oxidase gene from Arabidopsis thaliana enhanced the photosynthesis capacity in Brassica napus L. J. Plant Biol. 54: 23-32.

Zhou B, Lin JZ, Peng WS, Peng D, et al. (2012). Dwarfism in Brassica napus L. induced by the over-expression of a gibberellin 2-oxidase gene from Arabidopsis thaliana. Mol. Breed. 29: 115-127. 